\title{
Retinoblastoma H0 Finding v8
}

National Cancer Institute

\section{Source}

National Cancer Institute. Retinoblastoma HO Finding v8. NCI Thesaurus. Code C140728.

Normal RB1 alleles in blood tested with demonstrated high-sensitivity assays. (from AJCC 8th Ed.) 